\title{
Evaluation of a Prospective Study on Trifocal Toric Intraocular Lens Implantation in Patients with Cataract and High Corneal Astigmatism
}

\author{
Merve Bozkurt Gencer ${ }^{1}$, Hikmet Basmak ${ }^{2}$, Erdogan Yasar $^{3}$, Ozkan Onal ${ }^{4}$ \\ ${ }^{1}$ Medical Doctor, Dinar State Hospital, Ophtalmology Clinic, Afyonkarahisar/Turkey \\ ${ }^{2}$ Professor, Osmangazi University Medicine Faculty, Ophthalmology Department, Eskisehir/Turkey \\ ${ }^{3}$ Assistant Professor, Aksaray Medicine Faculty, Ophthalmology Department, Aksaray/Turkey \\ ${ }^{4}$ Medical Doctor, Ozalp State Hospital, Ophtalmology Clinic, Van/Turkey \\ *Corresponding Author: Merve Bozkurt Gencer, MD, Dinar State Hospital, Ophtalmology Clinic, \\ Afyonkarahisar/Turkey
}

\begin{abstract}
Purpose: To evaluate the visual acuity, quality of life, satisfaction, contrast sensitivities, glare and depth perception of patients who underwent trifocal IOL implantation.

Methods: 40 eyes of 20 patients were included in this prospective study. After intermittent surgery for both eyes with corneal astigmatism(less than or equal to $1.00 \mathrm{D}$ ), trifocal toric IOL implantation was performed using a digital-mounted marking system. Detailed anterior and posterior segment examinations of study patients were performed in preoperative and post operative 1.week, 1.month, 3.month and 6.month periods; refraction, vision-corrected and uncorrected(distance-intermediate-near) best corrected visual acuity of patients were measured; keratometric measurements and intraocular pressure measurement and finally visual function scale(NEI-VFQ-25) were performed. And also in 3rd and 6th month contrast sensitivity, glare tests (Vector Vision CSV-1000E test), near-intermediate (the Titmus Stereotest) and distance steropsis (Distance Randot Stereotest) were performed for study patients.
\end{abstract}

Results: The mean age of 20 study patients ( 7 male and 13 female) was $63.7 \pm 11.11$ (47-81 ages). At postoperative 6.month, the best corrected distance, intermediate and near vision acuites of 40 eyes were $0.05 \pm 0.06 \log M a r, 0.14 \pm 0.06 \log M a r$ and $0.12 \pm 0.04 \log M a r$ respectively. These results were statistically significant according to preoperative measurements $(p<0.001$ ). The mean spherical value was $-0.13 \pm 0.40$; the mean cylindrical value was $0.48 \pm 0.33$ and spherical equivalent means were $-0.42 \pm 0.49$ at postoperative 6. month $(p=0.036, p<0.001, p=0.011$, respectively). The best contrast sensitivities and glare values were observed at 6 CPD spasial frequencies postoperative $3 \mathrm{rd}$ and 6 th month $(1.80 \pm 0.24 \log$ and $1.56 \pm 0.26 \log$, respectively). Postoperative 6.month near and distance stereopsis measurements were $40 \mathrm{~cm}: 57.5 \pm 24.25$ arc/sec, $80 \mathrm{~cm}: 79 \pm 28.45 \mathrm{arc} / \mathrm{sec}, 2 \mathrm{mt}: 153 \pm 77.94 \mathrm{arc} / \mathrm{sec}$ and $3 \mathrm{mt}: 270 \pm 112.85 \mathrm{arc} / \mathrm{sec}$, respectively. Visual function questionnaire scores in postoperative $3 \mathrm{rd}$ and 6 th month were found significantly higher, $88.20 \pm 8.87$ and $88.18 \pm 3.97$ ( $p=0.017$ and $p=0.025$, respectively).

Conclusions: In this study, we evaluated 6 month results of trifocal IOL implantation and found that near, intermediate and distance stereopsis of patients were sufficient and quality of life was satisfactory.

Keywords: Cataract, astigmatism, trifocal toric intraocular lens, stereopsis.

\section{INTRODUCTION}

While visual acuity of patients can be increased, refractive errors can also be corrected by cataract surgery. The visual expectations of patients are rapidly increased by using recently developed new intraocular lenses and modern phacoemulsification surgery [1]. A significant increase in visual acuity and visual satisfaction can be achieved by using conventional spheric monofocal and multifocal lenses and glasses addiction can be reduced sufficiently but this may not be sufficient in patients with high corneal astigmatism [2]. Nearly 15-29\% of patients with cataract also have $1.50 \mathrm{D}$ or more corneal astigmatism [3]. Although some methods such as vertical corneal incision and limbal relaxant incision have been performed to date for correcting astigmatism during cataract surgery, only limited and unpredictable 
improvement has been achieved due to individual difference of incision site healing process [4-5]. Toric intraocular lenses (IOL) are predictable and easy-to-use options for correction of astigmatic refractive error in patients who don't want glasses after cataract surgery [6-7].

Trifocal toric lenses have semi-apodisation mechanism where optical diffraction is arranged for distance, intermediate and near and they increase depth of focus(EDOF). In addition, these lenses can correct corneal astigmatism (1.00 D and above) by a toric plug on optic. As a result these lenses intend the best and hasslefree vision on distance ( 6 meters and more), intermediate $(80 \mathrm{~cm})$ and near $(40 \mathrm{~cm})$ without glasses. These lenses have $+1.50 \mathrm{D}$ at intermediate and $+3.00 \mathrm{D}$ at near through their active diffractive structures and concentric rings. Trifocal toric IOLs are alternative options for appropriate patients due to low residual astigmatism after cataract surgery with favorable funtional results at distance, intermediate and near and high quality of life [89]. In addition, the funtional succes was found higher in surgeries where the implanted trifocal toric IOL rotation is 5 degree or less [10]. Glasses addiction become virtually eliminable in cataract surgery with the introduction of toric and then trifocal toric lenses [11-12]. Therefore, trifocal toric lenses have a high-performance vision at both intermediate or near distances without affecting distance vision [13]. The gain in intermediate vision provides a significant increase in quality of life [14]. We didn't find a comprehensive study on stereopsis values of these lenses, especially at intermediate and distance in literature.

So we evaluated the visual acuity, astigmatism, quality of life, patient satisfaction, contrast sensitivity, glare and depth perception of patients who underwent trifocal toric IOL implantation.

\section{Patients and Methods}

Our study was campatible to principles of Helsinki Declaration and Ethics Committee of Osmangazi University, Eskişehir approved the study (No: 80558721/122). Patients who admitted to Ophthalmology Clinic of Osmangazi University Medical Faculty, Eskişehir with low vision between September 2016 and May 2017 were examined; patients with cataracts and best corrected distance visual acuity of 0,5 and below in Snellen chart were included in the study. Patients with diabetes mellitus, hypertension, optic neuritis, glaucoma, diabetic retinopathy, age related macular degeneration, pseudo exfoliation, pterygium, strabismus, corneal nephelion and ophthalmic surgery history were excluded. In patients with corneal astigmatism (topographic measurements were bilaterally $1.00 \mathrm{D}$ and above), after intermittent cataract surgery on both eyes Acriva ReviolTri-ED (Amsterdam, Netherland) trifocal toric IOL was applied with Verion digital microscope mounted marking system (Alcon, USA). Ophthalmologic examinations of patients were performed in preoperative and postoperative periods in detail. Refraction and intraocular pressure (IOP) were measured (NIDEK Tonoref II, 2015, Maehama, Gamagori, Aichi, Japan). The best uncorrected and corrected distance visual acuity were measured with LogMar visual scala at 6 meters; the best uncorrected and corrected intermediate visual acuity were measured with $\log M a r$ at $80 \mathrm{~cm}$ and the best uncorrected and corrected near visual acuity were measured with $\log M a r$ at $40 \mathrm{~cm}$. Anterior and posterior segment examinations of all patients were performed using tropicamide 1\%. Anterior segment photos (TopconsI-D7, SN: 1613331, Japan) and macular OCT images (Zeiss Cirrus HD) were taken and fundus photos were recorded with Optos 200Tx. Corneal astigmatism of patients were determined by Kappa angle measurement (Haag-Streit Lensstar LS900). Patients with corneal astigmatism values of 1.00D and above and Kappa angle of 0.40 and below were included in study.

For IOL spherical and cylindrical powers of patients who will undergo implantation of trifocal toric IOL Haag-StreitT-Cone was added to LensstarLS 900. To determine IOL spherical power, emetropy was targetted by using SKR-T and Barret formulas. Cylindrical power was calculated by using an online module in $\mathrm{http} / / /$ easytoriccalculator.com/acriva.php?lang= en. Quality of life in preoperative and postoperative periods were measured by NEIVFQ-25 visual function scale.

Finally in preoperative periods, measurements were performed on Alcon VERION digital microscope-mounted marking device which digitally marks the location of the incision during the surgery, the size of capsulorhexis to 
Evaluation of a Prospective Study on Trifocal Toric Intraocular Lens Implantation in Patients with Cataract and High Corneal Astigmatism

be opened in the lens capsule and the position of the cylindrical IOL in the eye (within the lens capsule); $5.5 \mathrm{~mm}$ capsule opening was considered sufficient in the study. When the cylindrical IOL was placed in the capsule, stabilization was achieved by placing the IOL on the determined according to previous keratometric measurements. Results were evaluated postoperative 1.day, 1.week, 1.month, 3.month and 6.month. On the first operative day, only biomicroscopic examination and refraction measurements were performed for early detection of abnormal astigmatic values due to relation in IOL position. Refraction, IOP, distance-intermediate-near uncorrected and corrected best visual acuity (BCVA) were measured on postoperative 1.week and 1.month. After detailed anterior-posterior segment examinations, postoperative keratometry was measured and the pupil was dilated with tropicamide $1 \%$ to detect presence of rotation in IOL. For objective measurement of IOL rotation, method proposed by Wolffson and Buckhurst in their 2010 study was used [16]. Similar ophthalmologic examinations and measurements were also performed at the $3 \mathrm{rd}$ and 6th month follow-ups after all eye surgeries of patients. Also patient satisfaction, need for glasses and glare symptoms were evaluated by asking patients. Contrast sensitivity and glare were measured by VectorVision CSV-1000E Contrast Sensitivity Test. Measurements were performed under normal room illumination conditions after correction for BCVA. Glare was measured with 2 halogen lamps attached to CSV $1000 \mathrm{E}$ (by turning on lamps under photopic conditions). Near stereopsis $(40 \mathrm{~cm}$ and $80 \mathrm{~cm}$ ) was measured by using "Titmus Stereotest" and distance stereopsis(2m and $3 \mathrm{~m}$ ) by "Distance Randot Stereotest". Tests were performed by using binocular and polarizing glasses and the latest arc/sec was recorded.

IBM SPSS for Windows version 21.0 was used for statistical analysis. Numerical variables were defined as mean \pm standart deviation using descriptive statistical analysis. Normal distribution of numerical data was evaluated with ShapiroWilk test. Pairedsample t-test was used to compare the mean values of one variable observed in two different cases. $\mathrm{p}<0.05$ was considered statistically significant.

\section{RESULTS}

40 eyes of 20 patients ( 7 male, 13 female) were included in the study; mean age of patients was $63.7 \pm 11.11$ (47-81 years). Surgeries were performed by the same surgical team using phacoemulsification technic and no complication observed. Preoperative Kappa angle was $0.32 \pm 0.18$. The best uncorrected and corrected distance visual acuity levels of patients at preoperative and postoperative 1st week, 1st month, 3rd month and 6th month are summarized in Table 1.

Table1. Preoperative and postoperative the best uncorrected and corrected distance visual acuity levels

\begin{tabular}{|c|c|c|c|c|c|}
\hline & $\begin{array}{c}\text { LogMar } \\
\text { Mean } \pm \text { SD }\end{array}$ & $\begin{array}{c}\text { Snellen } \\
\text { Mean } \pm \text { SD }\end{array}$ & $\begin{array}{c}\text { LogMar } \\
\text { Mean } \pm \text { SD }\end{array}$ & $\begin{array}{c}\text { Snellen } \\
\text { Mean } \pm \text { SD }\end{array}$ & $\mathbf{P}$ \\
\hline Preop & UDVA:0.86 \pm 0.19 & $0.13 \pm 0.16$ & CDVA:0.67 \pm 0.22 & $0.23 \pm 0.17$ & \\
\hline 1.week & UDVA:0.18 \pm 0.06 & $0.74 \pm 0.12$ & CDVA:0.14 \pm 0.07 & $0.76 \pm 0.21$ & $<0.001$ \\
\hline 1.month & UDVA:0.12 \pm 0.05 & $0.78 \pm 0.08$ & CDVA:0.09 \pm 0.06 & $0.82 \pm 0.10$ & $<0.001$ \\
\hline 3.month & UDVA:0.07 \pm 0.05 & $0.89 \pm 0.11$ & CDVA:0.06 \pm 0.06 & $0.91 \pm .0 .09$ & $<0.001$ \\
\hline 6.month & UDVA:0.07 \pm 0.05 & $0.89 \pm 0.11$ & CDVA:0.05 \pm 0.06 & $0.91 \pm .0 .06$ & $<0.001$ \\
\hline
\end{tabular}

UDVA: Uncorrected distance visual acuity,

CDVA: Corrected distance visual acuity,

Preop: Preoperative

\section{SD: Standard deviation}

Postoperative 1st week, 1st month, 3rd month and 6th month follow-ups showed a statistically significant increase in distance visual acuity compared to preoperative values $(\mathrm{p}<0.001)$.
The best uncorrected and corrected intermediate visual acuity levels of patients at preoperative and postoperative 1 st week, 1 st month, 3rd month and 6th month are summarized in Table 2. 
Evaluation of a Prospective Study on Trifocal Toric Intraocular Lens Implantation in Patients with Cataract and High Corneal Astigmatism

Table2. Preoperative and postoperative the best uncorrected and corrected intermediate visual acuity levels

\begin{tabular}{|l|c|c|c|c|c|}
\hline & $\begin{array}{c}\text { LogMar } \\
\text { Mean } \pm \text { SD }\end{array}$ & $\begin{array}{c}\text { Snellen } \\
\text { Mean } \pm \text { SD }\end{array}$ & $\begin{array}{c}\text { LogMar } \\
\text { Mean } \pm \text { SD }\end{array}$ & $\begin{array}{c}\text { Snellen } \\
\text { Mean } \pm \text { SD }\end{array}$ & P \\
1.week & UIVA:0.33 \pm 0.08 & $0.48 \pm 0.11$ & CIVA:0.23 \pm 0.66 & $0.58 \pm 0.21$ & $<.19 \pm 0.20$ \\
1.month & UIVA:0.24 \pm 0.07 & $0.62 \pm 0.09$ & CIVA:0.15 \pm 0.07 & $0.71 \pm 0.12$ & $<\mathbf{0 . 0 0 1}$ \\
3.month & UIVA:0.16 \pm 0.07 & $0.70 \pm 0.10$ & CIVA:0.14 \pm 0.06 & $0.72 \pm 0.10$ & $<\mathbf{0 . 0 0 1}$ \\
6.month & UIVA:0.15 \pm 0.06 & $0.71 \pm 0.12$ & CIVA:0.14 \pm 0.06 & $0.72 \pm 0.10$ & $<\mathbf{0 . 0 0 1}$ \\
\hline
\end{tabular}

UIVA: Uncorrected intermediate visual acuity,

CIVA: Corrected intermediate visual acuity,

Preop: Preoperative

SD: Standard deviation

Postoperative 1st week, 1st month, 3rd month and 6th month follow-ups showed a statistically significant increase in intermediate visual acuity compared to preoperative values $(\mathrm{p}<0.001)$.

The best uncorrected and corrected near visual acuity levels of patients at preoperative and postoperative 1 st week, 1 st month, 3rd month and 6th month are summarized in Table 3.

Table3. Preoperative and postoperative the best uncorrected and corrected near visual acuity levels

\begin{tabular}{|l|c|c|c|c|c|}
\hline & $\begin{array}{c}\text { LogMar } \\
\text { Mean } \pm \text { SD }\end{array}$ & $\begin{array}{c}\text { Snellen } \\
\text { Mean } \pm \text { SD }\end{array}$ & $\begin{array}{c}\text { LogMar } \\
\text { Mean } \pm \text { SD }\end{array}$ & $\begin{array}{c}\text { Snellen } \\
\text { Mean } \pm \text { SD }\end{array}$ & P \\
1.week & UNVA:0.81 \pm 0.13 & $0.15 \pm 0.2$ & CNVA:0.64 \pm 0.16 & $0.24 \pm 0.16$ & \\
1.month & UNVA:0.38 \pm 0.05 & $0.41 \pm 0.08$ & CNVA:0.28 \pm 0.05 & $0.52 \pm 0.07$ & $<\mathbf{0 . 0 0 1}$ \\
3.month & UNVA:0.18 \pm 0.09 & $0.67 \pm 0.11$ & CNVA:0.13 \pm 0.07 & $0.72 \pm 0.13$ & $<0.0001$ \\
6.month & UNVA:0.15 \pm 0.06 & $0.74 \pm 0.08$ & CNVA:0.12 \pm 0.04 & $0.78 \pm 0.03$ & $<\mathbf{0 . 0 0 1}$ \\
\hline
\end{tabular}

UNVA: Uncorrected near visual acuity,

CNVA: Corrected near visual acuity,

Preop: Preoperative

SD: Standard deviation

Postoperative 1st week, 1st month, 3rd month and 6th month follow-ups showed a statistically significant increase in near visual acuity compared to preoperative values $(\mathrm{p}<0.001)$.

Preoperative and postoperative spherical mean values, cylindrical mean values and spherical equivalent mean values of patients are summarized in Table 4.

Table4. Preoperative and postoperative refraction and keratometric measurements

\begin{tabular}{|l|c|c|c|}
\hline & $\begin{array}{c}\text { Preop } \\
\text { Mean } \pm \text { SD }\end{array}$ & $\begin{array}{c}\text { Postop } \\
\text { Mean } \pm \text { SD }\end{array}$ & P \\
Spherical values & $-1.39 \pm 3.53$ & $-0.13 \pm 0.40$ & $\mathbf{0 . 0 3 6}$ \\
Cylindrical values & $1.91 \pm 2.16$ & $0.48 \pm 0.33$ & $\mathbf{0 . 0 1 1}$ \\
Spherical equivalent & $-2.36 \pm 4.39$ & $-0.41 \pm 0.49$ & $<\mathbf{0 . 0 0 1}$ \\
\hline
\end{tabular}

SD: Standard deviation

Spherical, cylindrical and spherical equivalent measurements of patients were statistically improved $(\mathrm{p}=0.036, \mathrm{p}=0.011, \mathrm{p}<0.01$, respectively).
Contrast sensitivity and glare tests were performed at 3rd and 6th month; results of these tests and curves of patients are shown in Figure 1. 
Evaluation of a Prospective Study on Trifocal Toric Intraocular Lens Implantation in Patients with Cataract and High Corneal Astigmatism

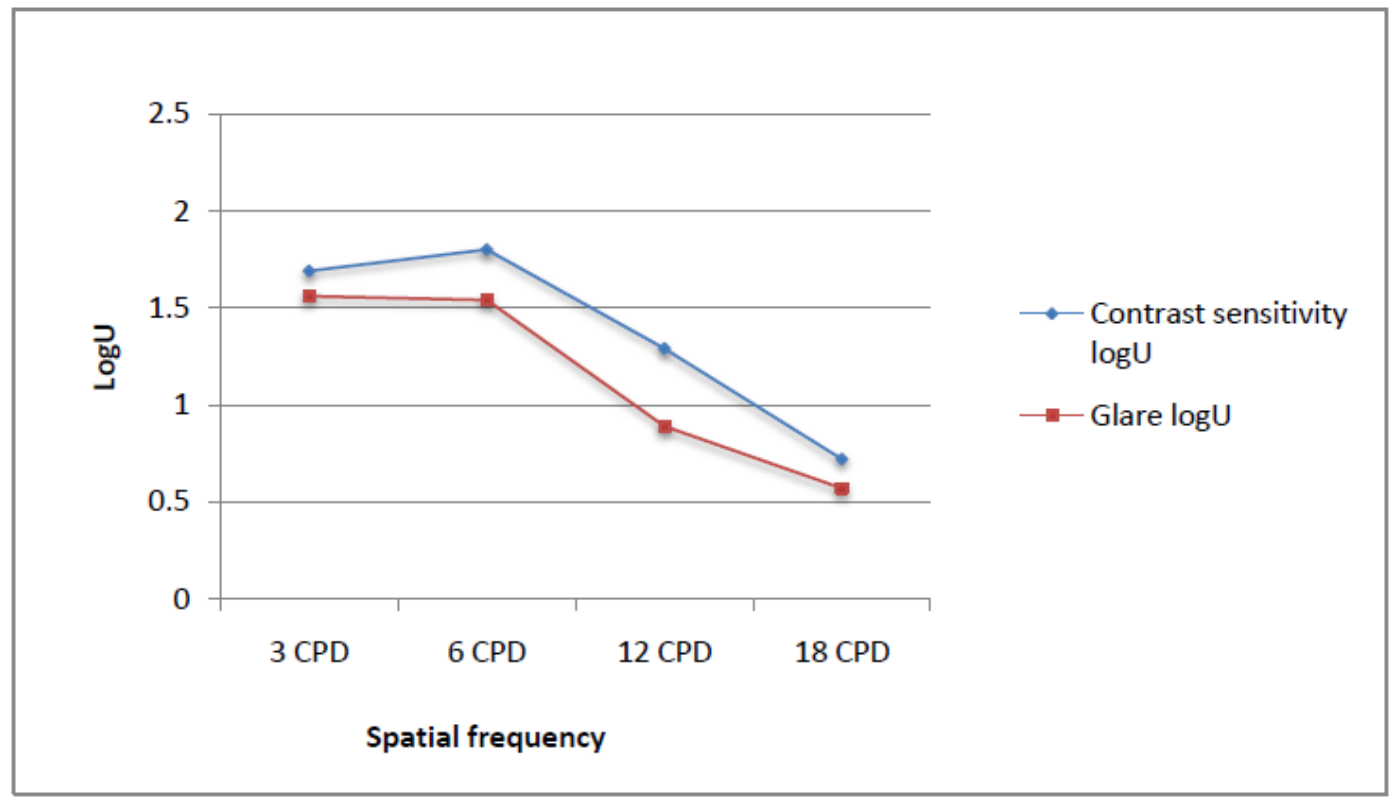

Graph1. Postoperative 6th month curve of contrast sensitivity and glare

Results of contrast sensitivity and glare tests were not statistically significant at 3rd and 6th month ( $p>0.05)$; best results were obtained at 6 CPD spasial frequency.

Preoperative mean visual function scale questionnaire (NEI-VFQ-25) scores were 62.81 \pm 16.24 (min: 27.00, max: 88.80). Mean repetetive scores were $88.20 \pm 8.87$ (min: 67.12, max: 95.90) at 3rd month after both eye surgeries. And scores of repeated questionnaire at 6th month were $88.18 \pm 3.97$ (min: 81.6, max: 95.8). NEI-VFQ-25 patient satisfaction questionnaire results showed a significant increase at postoperative 3rd and 6th month compared to preoperative ones $(\mathrm{p}=0.017$ and $\mathrm{p}=0.025$ ).

2 patients (10\%) were prescribed near glasses and 2 others $(10 \%)$ were prescribed distance glasses. 16 patients $(80 \%)$ had no need glasses. Given the patient satisfaction questionnaire, 17 patients $(85 \%)$ were very satisfied with their surgeries and visual performance; other 3 patients $(15 \%)$ were only satisfied. Given the glare complaints, 16 patients $(80 \%)$ had no complaints but 3 patients (15\%) reported mild and 1 patient (5\%) moderate glare.

"Titmus Stereotest" for near and intermediate $(40 \mathrm{~cm}$ and $80 \mathrm{~cm})$ and "Distance Randot Stereotest" for distance $(2 \mathrm{~m}$ and $3 \mathrm{~m})$ were performed at 3rd and 6th month follow-up. Near and distance stereopsis at $3 \mathrm{rd}$ month were $40 \mathrm{~cm}$ : $63.3 \pm 23.9 \mathrm{arc} / \mathrm{sec}, 80 \mathrm{~cm}: 76 \pm 25.6 \mathrm{arc} / \mathrm{sec}, 2 \mathrm{~m}$ : $153 \pm 80.5 \mathrm{arc} / \mathrm{sec}$ and $3 \mathrm{~m}: 266 \pm 113.7 \mathrm{arc} / \mathrm{sec}$, respectively. At 6th month follow-up near and distance stereopsis were $40 \mathrm{~cm}: 57.5 \pm 24.25$ arc/sec, $80 \mathrm{~cm}: 79 \pm 28.45 \mathrm{arc} / \mathrm{sec}, 2 \mathrm{~m}: 153 \pm 77.94$ $\mathrm{arc} / \mathrm{sec}$ and 3m: $270 \pm 112.85 \mathrm{arc} / \mathrm{sec}$, respectively and no significant difference was found $(\mathrm{p}>0.05)$.

\section{DISCUSSION}

As a result, while the best preoperative corrected distance-intermediate-near visual acuity of 40 eyes were $0.67 \pm 0.22 \log M a r$, $0.71 \pm 0.15 \log$ Mar and $0.64 \pm 0.16 \log$ Mar; at postoperative 6th month the best corrected distance-intermediate-near visual acuity of 40 eyes who underwent trifocal toric IOL implantation were found $0.05 \pm 0.06 \log$ Mar, $0.14 \pm 0.06 \log$ Mar and $0.12 \pm 0.04$ logMar, respectively $(\mathrm{p}<0.001)$. In another study, Mojzis et al. implanted AT LISA 939M/MP trifocal toric IOL in 30 eyes of 16 patients and reported visual acuities at postoperative 3rd month as follows: distance: $0.03 \pm 0.11 \quad \log M a r$, intermediate: $0.08 \pm 0.11$ logMar and near: $0.16 \pm 0.09 \log$ Mar, respectively [9].In a study of Kretz and et al.,56 eyes of 28 patients were implanted AT LISA 939M/MP trifocal toric IOL and visual acuities of 3rd month follow-up were found as follow: monocular distance: $0.13 \pm 0.15$ logMar, intermediate: $0.08 \pm 0.15$ logMar and near: $0.13 \pm 0.18 \log$ Mar [17] In our study, we observed a significant increase in visual acuity similar to literature.

In our study, at postoperative 6th month mean spheric value of patients were found $0.131 \pm 0.404$; mean cylindrical value was $0.481 \pm 0.334$ and mean spherical equivalent was 
$-0.418 \pm 0.491$. Mojzis et al. reported the mean spheric value $-0.28 \pm 0.42$, mean cylindrical one $0.35 \pm 0.27$ and mean spherical equivalent $0.45 \pm 0.42$ at postoperative 3rd month [9]. In the study of Kretz et al. these values were as follows: mean spheric value $-0.17 \pm 0.51$, mean cylindrical value $-0.40 \pm 0.31$ and mean spherical equivalent $-0.37 \pm 0.50 .{ }^{17}$ Our postoperative spheric results were found to be similarly decreased compared to other Trifocal Toric IOL studies.

In our study the highest contrast sensitivity was observed at $6 \mathrm{CPD}$ spatial frequency $(1.80 \pm 0.24$ $\log \mathrm{U}$ ) in al patients under photopic conditions and contrast sensitivity decreased at increasing spatial frequencies. Kretz et al. [17] and Mojzis et al.[13] also reported the highest contrast sensitivity at 6 CPD spatial frequency. Unlike our study, Voskresenskaya et al. reported the highest contrast sensitivity at 3 CPD spatial frequency.[14] Contrast sensitivity curve of our patients was found to be highest at $6 \mathrm{CPD}$ spatial frequency similar to other studies and it was above normal levels at $3 \mathrm{CPD}$ and $6 \mathrm{CPD}$ frequencies(Normal contrast sensitivity $\log \mathrm{U}$ 3CPD: $1.56 \pm 0.15$, 6 CPD: $1.80 \pm 0.16,12$ CPD: $1.50 \pm 0.15$ and 18 CPD: $0.93 \pm 0.25$ ).

In our study we observed a statistically significant increase in visual quality of life according to visual funtion scale questionnaire (NEI-VFQ-25) $(\mathrm{p}<0.001)$. Removal of cataracts and IOL implantation may mainly improve the quality of life of our patients. Given the patient satisfaction, nearly all patients included in our study were very satisfied with their visual performance $(85 \%) .80 \%$ of our patients had no need glasses. In the study of Acar et al., it was reported that more than $90 \%$ of patients had no visual difficulties in their daily activities [18]. Voskresenskaya et al. reported that $95 \%$ of patients had no need glasses for near [14]. According to these reports, it is possible to consider that need for distance and near glasses in our patients decreased significantly similar to literature.

In our study $80 \%$ of patients reported no glare complaints; $15 \%$ of patients reported mild glare. Voskresenskaya et al. reported $16.7 \%$ glare complaints. ${ }^{14}$ Kretz et al. reported $45.7 \%$ halo and $30.4 \%$ glare complaints [17]. Relatively small size of our study compared to literature may affect the results. We may consider that AcrivaReviol Tri-ED trifocal toric IOLs and semiapodization technology significantly reduce light loss through the eye, leading to a significant reduction in glare complaints.

Mean near stereopsis value (Titmus Test) was found $57.5 \pm 24.25 \mathrm{arc} / \mathrm{sec}$. In a study of Teresa Ferrer-Blasco, 30 patients had bilateral multifocal IOL implantation and mean close stereopsis was reported $44.55 \pm 1.08 \mathrm{arc} / \mathrm{sec}$.[19] Our Titmus Test results were similar to literature. However, we couldn't find a study in literature on distance and intermediate stereopsis in patients who underwent trifocal IOL.

In conclusion, trifocal toric IOL implantation has satisfactory and predictable results. Trifocal toric IOL implantation is a promising surgical procedure due to elimination of glasses dependence, low astigmatism levels and high patient satisfaction. The limitation of our study may be relatively low number of patients. In our study, 6 month results of trifocal toric IOL implantation were evaluated and it was concluded that satisfactory results obtained especially in intermediate and distance stereopsis values had positive effects on quality of life of patients.

\section{REFERENCES}

[1] Yilmaz SG, Köse S, Palamar M, Eğrilmez S (2009) Our results of accommodative and multifocal intraocular lens implantation in patients with cataract. Turk J Ophthalmol 39(1): 4-16.

[2] Hoffer KJ (1980) Biometry of 7,500 cataractous eyes. Am J Ophthalmol. 90:360-8.

[3] Holland E, Lane S, Horn JD, Ernest P, Arleo R, Miller KM (2010) The AcrySof Toric intraocular lens in subjects with cataracts and corneal astigmatism: a randomized, subjectmasked, parallel-group, 1 year study. Opthhalmolog 117:2104-11.

[4] Tsinopoulos IT, Tsaousis KT, Tsakpinis D, Ziakas NG, Dimitrakos SA (2010) Acrylic toric intraocular lens implantation: a single center experience concerning clinical outcomes and postoperative rotation. Clin Ophthalmol 4:137-42.

[5] Kılıç İ, Akova YA, Akman A, Eğrilmez S (2012) The results of phacoemulsification and toric intraocular lens implantation in patients with high astigmatism and cataract. Turk J Ophthalmol 42(2):116-9.

[6] Mendicute J, Irigoyen C, Ruiz M, IllarramendiI, Ferrer-Blasco T, Montés-Micó R (2009) Toric intraocular lens versus opposite clear corneal incisions to correct astigmatism in eyes having cataract surgery. J Cataract Refract Surg 35(3):451-8. 
Evaluation of a Prospective Study on Trifocal Toric Intraocular Lens Implantation in Patients with Cataract and High Corneal Astigmatism

[7] Mingo-Botín D, Muñoz-Negrete FJ, Won Kim HR, Morcillo-Laiz R, Rebolleda G, Oblanca N (2010) Comparison of toric intraocular lenses and peripheral corneal relaxing incisions to treat astigmatism during cataract surgery. J Cataract Refract Surg 36(10):1700-8.

[8] Brožková M, Filipec M, Filipová L, Holubová A, Hlinomazová Z (2016) Outcomes of Trifocal Toric Lens Implantation in Cataract Patients. Cesk Slov Oftalmol. Fall 72(3):58-64.

[9] Mojzis P, Majerova K, Plaza-Puche AB, Hrckova L, Alio JL (2015) Visual outcomes of a new toric trifocal diffractive intraocular lens. J Cataract Refract Surg 41(12):2695-706.

[10] Höhn F, Tandogan T, Breyer DR, Kaymak H, Hagen P, Klabe K, Koss MJ, GerlM, Auffarth GU, Kretz FT (2015) Functional Results One Year after Implantation of a Bitoric, Trifocal Intraocular Lens. Klin Monbl Augenheilkd. 232(8):957-61.

[11] AcrySof Toric Single-Piece Natural IOL productinformation (2011) High Cylinder Power Intraocular Lenses. ForthWorth, TX: Alcon Laboratories Inc; p.1-15.

[12] Zhang JS, Zhao JY, Sun Q, Ma LW (2011) Distance vision after bilateral implantation of AcrySof toric intraocular lenses: a randomized, controlled, prospectivetrial. Int J Ophthalmol 4(2):175-8.

[13] Mojzis P P-GP, Liehneova I, Ziak P, Alio JL (2014) Outcomes of a new diffractive trifocal intraocular lens. J Cataract Refract Surg 2014;40:60-69.

[14] Voskresenskaya A, Pozdeyeva N, Pashtaev N, et al (2010) Initial results of trifocal diffractive IOL implantation. Graefes Arch Clin Exp Ophthalmol 248(9):1299-306.

[15] Ahmet Barış Toprak EE, Cenap Guler, Fatma Esin Başer, Hüseyin Mayalı. National Eye Institute Visual Functioning Questionnaire - 25 Turkishized Figure (VFQ-25/TR) 2000. 2004.

[16] Wolffsohn JS, Buckhurst PJ (2010) Objective analysis of toric intraocular lens rotation and centration. J Cataract Refract Surg 36(5):778-82.

[17] Kretz FT, Bastelica A, Carreras H, Ferreira T, Müller M, Gerl M, Gerl R, Saeed M, Schmickler S, Auffarth GU (2015) Clinical outcomes and surgeon assessment after implantation of a new diffractive multifocal toric intraocular lens. Br J Ophthalmol 99(3): 405-11.

[18] Acar B. DE, Simsek S (2016) Clinical outcomes of a new diffractivetrifocal intraocular lens with EnhancedDepth of Focus (EDOF). BMC Ophthalmology 16:208-17.

[19] Teresa Ferrer-Blasco DM-C, Santiago GarcíaLázaro, Alejandro Cerviño, Robert Montés Micó (2011) Stereopsis in bilaterally multifocal pseudophakic patients. Graefes Arch Clin Exp Ophthalmol 249:245-51.

Citation: Merve Bozkurt Gencer et.al, "Evaluation of a Prospective Study on Trifocal Toric Intraocular Lens Implantation in Patients with Cataract and High Corneal Astigmatism”, International Journal of Research Studies in Medical and Health Sciences. 2020; 5(2): 15-21.

Copyright: (C) 2020 Merve Bozkurt Gencer, This is an open-access article distributed under the terms of the Creative Commons Attribution License, which permits unrestricted use, distribution, and reproduction in any medium, provided the original author and source are credited. 